\title{
ERRATUM
}

\section{Erratum to: Functionalization of PEG-PMPC-based polymers for potential theranostic applications}

\author{
Ning CHEN ${ }^{1,2}$, Sidi $\mathrm{LI}^{1,2}$, Xueping $\mathrm{LI}^{1,2}$, Lixia $\operatorname{LONG}^{1,2}$, Xubo YUAN ${ }^{1,2}$, Xin $\operatorname{HOU}(\bowtie)^{1,2}$, \\ and Jin ZHAO $(\bowtie)^{1,2}$ \\ 1 Tianjin Key Laboratory of Composite and Functional Materials, Tianjin University, Tianjin 300350, China \\ 2 School of Materials Science and Engineering, Tianjin University, Tianjin 300350, China
}

(C) Higher Education Press 2021

Erratum to: Front. Mater. Sci. 2021, 15(2): 280-290

DOI: $10.1007 / \mathrm{s} 11706-021-0554-8$

In the original version of this article, the first affiliation "Tianjin Key Laboratory of Composite and Functional Materials, Tianjin 300350, China" should be "Tianjin Key Laboratory of Composite and Functional Materials, Tianjin University, Tianjin 300350, China".

The authors apologize for any confusion.

Received September 17, 2021

E-mails: houxin@tju.edu.cn (X.H.), zhaojin@tju.edu.cn (J.Z.) 